\title{
Design for Social Innovation: Distributed Economy, Collaborative Network and Creative Communities
}

\author{
Liliane Iten Chaves, ${ }^{\text {, }}$ \\ 1Universidade Federal Fluminense, Technincal Drawing Department, Rua Passo da Pátria, 156, Campus da Praia Vermelha \\ São Domingos, Niterói - RJ
}

\begin{abstract}
The article clarifies concepts incorporated to Design for sustainability, exposing differences and convergences among the terms. Distributed Economy, Collaborative Network and Creative Communities are concepts linked to Design for Social Innovation. The article begins by defining the context in which Social Innovations are understood as beneficial for the environment and for social restructuring. It presents a concept of Design for Social Innovation and, from a brief bibliographical review, describes how the other concepts (Distributed Economy, Collaborative Networks and Creative Communities) are related to this theme and to the Design for Sustainability field.
\end{abstract}

Keywords. Design for Social Innovation, Design for Sustainability, Distributed Economy, Collaborative Network, Creative Communities

\section{Introduction}

Research in Design for Sustainability has advanced to issues, other than product design, extending its vision for the joint project of Product-Service Systems (PSS) and for understanding the role and practice of the designer in initiatives that lead to more sustainable lifestyle changes, such as Social Innovations, Distributed Economy, Collaborative Networks and the Creative Communities.

These terms, even in media and widely used nowadays, still cause doubts when it comes to Design. This article, therefore, aims to present some considerations on these terms, which are used in the research and study of Design for Sustainability.

Design for Sustainability is practice, training and research in Design, which in many ways aid to sustainable development (Manzini and Vezzoli, 2002). The last one was first defined at the UN Conference on Environment and Development (CNU MAD), held in Rio de Janeiro in 1992 (ECO '92), as "a development aimed at meeting the present needs without compromising future generations capabilities to meet their own needs. "

Although, it is an open concept and criticized by many, sustainable development brings in itself implicit arguments related not only to the scarcity of natural resources (environmental pillar of sustainability), but also to the need for social equality (social pillar of sustainability), income redistribution (economic pillar of sustainability) and, finally, respect for the differences and increase in land values, made by local knowledge and culture (cultural pillar of sustainability).

In this sense, the role of the designer has glimpsed two levels of interference, the first at the level of operational management and the other at the strategic level, as described below:

- redesign of the existing one: when it comes to product Design and manufacturing with less environmental impact, that is, an insertion of incremental innovations; - radical changes: that is, the insertion of radical innovations that foster new lifestyles, with solutions that lead to the dematerialization of new products.

When, in the 1970s, the understanding that natural resources are finite began, the Design professional, concerned about the environment, focused his actions on the creation and development of products with a lower environmental impact, following strategies such as (MANZINI And VEZZOLI, 2002): minimizing the use of resources, choosing resources with low environmental impact, optimizing product lifetime, extending material lifetime and facilitating disassembly.

However, the environmental redesign of existing products (MANZINI and VEZZOLI, 2002) will not be able to make the necessary changes to preserve life on the planet, as some scientists say (MEADOWS et al, 2007). The transformation requires radical changes and a discontinuity in consumption and production patterns. Thus, design for sustainability has focused on the search for radical innovations, such as the dematerialization of products, the offer of solutions through services and the creation of alternatives for a more responsible consumption.

\footnotetext{
${ }^{\mathrm{a}}$ Corresponding author: $\underline{\text { lilianeitenchaves@id.uff.br. }}$
} 
Among these possibilities there is the Product + Service Systems (PSS), defined as the result of an innovation strategy, redirecting the business focus from Design, turning the simple sale of physical products to the sale of PSS, able to attend jointly and integrally customer demands (Manzini \& Vezzoli, 2002).

It is believed that the Product + Service Systems have the potential to lead to the adoption of more sustainable positions. From VEZZOLI's (2010) classification on eco-efficient PSS types, it becomes clearer to observe the direct and indirect advantages in environmental terms:

- Services providing added value to the product life cycle, in which additional services are provided to ensure product life cycle performance, such as maintenance, repair, upgrade, product collection at disposal, etc. In this case, the product will have a longer duration and will be better used throughout its use phase. Moreover, the company responsible will give a more coherent direction to the product in its disposal, with better reuse of parts and materials.

- Services that provide final results to customers, in other words, the customer does not participate in the execution of the service, he receives the result done. An example would be the delivery of washed laundry by a laundry establishment. In this case, the company is not only concerned about the duration and better equipment efficiency, but will have a "know how", in order to make better use of the inputs.

- Services that provide facilitating platforms for customers: in this case, the provider company provides access to products, tools, opportunities or capabilities that enable the customer to participate and achieve the desired result. In relation to sustainability, this kind of service allows the restructuring of the social network, the increase in knowledge value and the increase of durability, once the product can be reconfigured with the user's choice, creating esteem value.

Supplier companies are expected to adopt more ecoefficient standards, aiming at optimizing the product life cycle, extending the life of materials and minimizing the use of resources. Moreover, these systems can result in better use of technology and faster replacement of products that are outdated by newer and more ecoefficient ones, since the company is concerned about the performance of its devices (Manzini \& Vezzoli, 2002).

As shown above, PSSs do not necessarily need to be designed to perform sustainably, as environmental and social benefits may occur indirectly. However, in general, the solutions adopted by the companies are considered "Win Win", which are solutions where the company wins both in environmental terms and in economic terms.

Even being considered promising in environmental and social terms, the design of eco-efficient systems requires new skills of the designer. In Brazil, by tradition, the teaching of Design is related to the development of new products and only recently has been offering service design related contents, by this way, requiring new capabilities of the designer (Vezzoli, 2010):
- Promote and facilitate new interactions with new socio-economic partners.

- Promote and facilitate participatory design between different partners.

- Create visualization tools that allow results and processes communication.

- Guide the created system to an eco-efficient solution.

The designer begins to work with intangible elements and therefore requires new tools and methods for the PSS's creation, development and analysis'. New information technologies and networking have created new structuring possibilities for designing and producing methods, it inserts new possibilities, and therefore new learning needs.

\section{Social innovation and distributed economy}

The scarcity of natural resources and the demographic explosion, among other problems, will cause our production and consumption model to undergo through radical changes, which can be adopted drastically or through a more harmonious social learning (MANZINI, 2014, P. 63). Social Innovation is described by the author as:

\footnotetext{
... changes in the way individuals or communities act in order to achieve a result (ie, to solve a problem or to generate opportunities). These innovations are driven by behavioral changes (rather than by technology or market) and emerge more from bottom-up than from top-down processes. If the form of obtaining the result is entirely new (or if the result is totally new), we can refer to it as radical social innovation. "(MANZINI, 2012, page 63$)^{1}$. Author's translation.
}

In this sense, local initiatives may play a key role in social restructuring to achieve a new standard. These initiatives are called promising cases of social innovation, leading to a "more interested movement towards a more sustainable daily life" (Manzini, 2012, p. 63).

There are examples of initiatives where, in different ways and for different reasons, people have reoriented their attitudes and expectations in a direction that seems coherent with the principles of social and environmental sustainability (MANZINI, 2012, page $63)^{2}$.

These cases have a flexible and open organizational capability, they are a large laboratory of possible futures, where one can observe, learn and recognize the promising cases for sustainability. They are considered cases of Product-Service Systems when the creation, management and practice are done by the community.

Two branches of social innovation are particularly important in this article: creative communities and collaborative networks.

\footnotetext{
${ }^{1}$ Translated by the author.

${ }^{2}$ Translated by the author.
} 


\subsection{Creative communities}

By creative communities are meant cases of people capable of acting outside the dominant pattern production and consumption, establishing social relations with their community in order to solve a problem of daily life, offering their time, their skills and their knowledge. These people are involved in increasing their land value, restructuring the social network and restablishing a new meaning to the common goods. These represent positive actions in relation to sustainability, since they respond to the three working hypotheses presented by MANZINI (2008, p. 47-51), related to well-being and the current environmental and social crisis.

- Common goods crisis: they are goods that belong to everyone and belong to no one, as is the case of water and public places such as squares and parks, but also security and sense of belonging. These goods cannot be bought and sold; therefore, they were placed outside the priorities of the hegemonic standard.

- Disappearance of slow and contemplative time: this is the time to "do nothing", or time to contemplate slowly and deeply the qualities of our lives. With the saturation of the tasks and the acceleration of actions, the time for reflection became scarce.

- Dissemination of remedial goods: they are considered by the author "products or services that try to make acceptable a life context that is in itself highly deteriorated". They are goods and services for private use and consumption that are based on the improvement of life (new washing machines, bottle of mineral water, tourism packages, etc.). "The common sense between these goods is that their use or consumption does not improve life quality or opens new possibilities for customers" (MANZINI, 2008, p.50).

\subsection{Collaborative Network}

Collaborative network is understood as a form of organization in which collaborative projects are carried out by people connected through the new information technologies. This model of organization arose from Open Source Software, when software became available for free, since any changes and improvements were shared with all other users (Manzini, 2012). Nowadays, this model is used for other fields of applications, joining people geographically distant, but have a common motivation, creating new projects.

In spite of being different phenomena, these two models of social organization possess a tendency to unite, creating a new business model with flexible and decentralized units that connect synergistically to one another throughout local resources. This is the so-called Distributed Economy (DE) (Johnson et al., 2005).

\subsection{Distributed economy}

In the Distributed Economy, small-scale local units are organized into groups, forming producing networks that, using local resources (raw materials, knowledge, culture, etc.), are able to reach a global, flexible and resilient way to respond quickly to new challenges. Distributed economy is a concept that has been developed in response to the current industrial production system and is has high chances to become a lever for regional development by introducing innovative strategies.

The most recent researches in Design for sustainability have directed their attention in understanding the role of the designer in the participation of these systems. Creating attractive conditions, facilitating the visualization of conditions and results, as well as developing interaction tools, are some of the possibilities. Moreover, by analysing these promising cases, we seek to "conceive and develop a set of facilitating solutions for the promotion of sustainability" (Manzini, 2012, p.62).

When well-designed, distributed economies represent a promising opportunity to achieve many benefits:

- Economical: reducing transport costs.

- Environmental: gains in efficiency and reduction of emissions.

- Ethical partner: democratization of access to goods and services, increase the participation and empowerment of the economy and local communities.

\section{Final considerations}

In Design for sustainability, the project of products with low environmental impact is already a well consolidated area for the designer, with innumerable tools and facilities. The social pillar of sustainability has been the main focus of researchers and the Design has been delving in creating and adapting tools for application and research. The social dimension points a quality in which the designer is expert: interaction between different skateholders from a team, being this team from a company, a community or a collective.

It is not possible to project or evaluate a social relation, although, it is possible to use and project tools that help developing communication, group projects and help directing these groups to a more friendly solution in environmental, social and cultural terms. In this sense, the designer that worries about sustainability has been using tools of strategic management, codesign, participatory design, etc. Moreover, classified as participants and collaborators of these social innovation initiatives are: creative communities, collaborative networks and distributed economy. 


\section{Acknowledgments}

The present work has been done with CNPq's (National Council of Scientific and Technological Development of Brazil) support (110845/2016-1).

\section{References}

JOHANSSON, A.; KISCH, P.; MIRATA, M.. Distributed Economies: a new engine for innovation. In: Journal of Cleaner Production, v. 13, p. 971-979, 2005.

MANZINI, E.; VEZZOLI, C. O desenvolvimento de produtos sustentáveis: os requisites ambientais dos produtos industriais. São Paulo: EDUSP, 2002.

MANZINI, E.; VEZZOLI, C. Product-Service Systems and Sustainability: opportunities for Sustainable Solutions, Paris: UNEP-United Nations Environment Programme, 2002.

MANZINI, E. Design para a Inovação Social $e$ Sustentabilidade: comunidades criativas, organizações colaborativas e novas redes projetuais. Rio de Janeiro: E-papers, 2008.

MANZINI, E. Comunidades Criativas, redes colaborativas e economias distribuídas: sinais promissores para um desenvolvimento sustentável. In: BARTHOLO, R. et al. (Org.) A Projetação e seus Horizontes: questões contemporâneas para a Engenharia de Produção. Rio de Janeiro: E-papers, 2012, p. 61 - 80. MEADOWS, D.: MEADOWS, D.: RANDERS, J. Limits to groth: the 30-year update. White River Junction: Chealsea Green, 2007.

VEZZOLI, C. Design de Sistemas para a Sustentabilidade. Salvador: EDUFBA, 2010. 